\title{
Inhibitory or excitatory? Optogenetic interrogation of the functional roles of GABAergic interneurons in epileptogenesis
}

\author{
Hui Ye ${ }^{*}$ (D) and Stephanie Kaszuba
}

\begin{abstract}
Alteration in the excitatory/inhibitory neuronal balance is believed to be the underlying mechanism of epileptogenesis. Based on this theory, GABAergic interneurons are regarded as the primary inhibitory neurons, whose failure of action permits hyperactivity in the epileptic circuitry. As a consequence, optogenetic excitation of GABAergic interneurons is widely used for seizure suppression. However, recent evidence argues for the context-dependent, possibly "excitatory" roles that GABAergic cells play in epileptic circuitry. We reviewed current optogenetic approaches that target the "inhibitory" roles of GABAergic interneurons for seizure control. We also reviewed interesting evidence that supports the "excitatory" roles of GABAergic interneurons in epileptogenesis. GABAergic interneurons can provide excitatory effects to the epileptic circuits via several distinct neurological mechanisms. (1) GABAergic interneurons can excite postsynaptic neurons, due to the raised reversal potential of GABA receptors in the postsynaptic cells. (2) Continuous activity in GABAergic interneurons could lead to transient GABA depletion, which prevents their inhibitory effect on pyramidal cells. (3) GABAergic interneurons can synchronize network activity during seizure. (4) Some GABAergic interneurons inhibit other interneurons, causing disinhibition of pyramidal neurons and network hyperexcitability. The dynamic, context-dependent role that GABAergic interneurons play in seizure requires further investigation of their functions at single cell and circuitry level. New optogenetic protocols that target GABAergic inhibition should be explored for seizure suppression.
\end{abstract}

Keywords: Epilepsy, GABAergic interneurons, Optogenetics

\section{Background}

One out of every 26 people is diagnosed with epilepsy during their lifetime, making it one of the most prevalent neurological disorders. $30 \%$ of these patients continue to have seizures despite the exhaustion of current pharmacological methods. Despite significant advances made in new pharmacological treatments, traditional anti-epileptic drugs show insufficient specificity in targeting particular cell types in the epileptic neural circuitry. The hyper-excitability of many neurons during a seizure is dynamic, demanding acute, precise temporal control of neuronal activities for effective treatment.

Optogenetic techniques are particularly suited to explore mechanisms of epileptogenesis, and could be

\footnotetext{
* Correspondence: hye1@luc.edu

Department of Biology, Loyola University Chicago, Quinlan Life Sciences

Education and Research Center, 1032 W. Sheridan Rd, Chicago, IL 60660, USA
}

used for future clinical treatment of seizures. The introduction of light-activated opsins can be made cell type specific, and their optical activation can be restrained precisely within a neural circuit. Optical excitation in cells can be achieved on a timescale of milliseconds, similar to that of seizure-like events. Recent studies have implemented this tool to reveal the neuronal mechanisms underlying seizures. It is possible to completely suppress seizure by optogenetic control of certain populations of neurons [1-3]. However, due to the largely unsolved complexity of seizure mechanisms, many issues still need to be addressed, including the selection of targeted cell types, its temporal precision, and optimized light stimulation parameters.

This review will focus on the functional implication of GABAergic interneurons in epileptogenesis, and current optogenetic approaches in seizure suppression with these types of neurons as the primary targets. 


\section{Excitatory/inhibitory balance in epileptogenesis}

Interactions between inhibitory and excitatory elements in a neural network shape its activity [4]. The unpredictable, synchronized firing of large populations of neurons is regarded as a consequence of an alteration in the excitatory/inhibitory balance within the neural circuitry. In support of this notion, mutations in at least 25 different human epilepsy-associated genes have been described, many of which encourage excitatory shifting [5]. Previous research indicates that hyper-excitability occurs during the transition to seizure when excitatory glutamatergic activity increases, while the inhibitory GABAergic synaptic input is weakened [6-9]. In global ischemia, both morphological and functional reorganizations happen in the CA3 network in the hippocampus. The excitatory-inhibitory balance shifts toward excitation, which leads to post-ischemic epileptiform activities [6]. In a low- $\mathrm{Mg}^{2+}$ model, both interneurons and pyramidal neurons in the CA1 area experience a change in intracellular signal integration during seizure transition. This is featured by the start of dominant inhibitory synaptic activity, followed by dominant excitatory synaptic activity prior to a seizure [7]. Recent studies also demonstrate alterations in various aspects of GABAergic neurons as inhibitory factors in seizure [10], which will be further discussed in the following sections.

\section{Traditional view of GABAergic interneurons in providing inhibitory effects to the epileptic circuitry}

A frequently studied cell type in epileptogenesis is the GABAergic interneuron. By releasing the neurotransmitter gamma-aminobutyric acid (GABA), these neurons are traditionally regarded as inhibitory to network activity. Interactions between interneuron populations and principal cells determine the neuro-mechanism of seizure. A well-received hypothesis is that during a seizure, the ability for GABA inhibition to counterbalance membrane depolarization and action potential firing is decreased, and this modification within the interneuronal network facilitates the synchronization of the principal cells. In support of this notion, abnormalities in inhibitory GABAergic function were found in several genetic and experimental epilepsy models $[11,12]$. In addition, De Lanerolle [13] reported the loss of hippocampal interneurons in human temporal lobe epilepsy (TLE). However, these anatomical changes during epilepsy alone are insufficient in determining whether GABA changes are adaptive or causal [14].

Functionally, altered GABAergic interneuron activity has been related to the synchronization and hyperexcitability of network activities in seizures [11, 15-17]. When the excitability of both parvalbumin- and somatostatinexpressing interneurons was impaired in mouse neocortex, it led to a disinhibition of the cortical network [18]. Similarly, the action potential initiation mechanism was impaired in GABAergic interneurons of a mouse model that expresses mutated human $\mathrm{Na}(\mathrm{V})_{1.1}$ gene, resulting in a hyperexcitable network [17]. When the functions of voltage-dependent sodium channels are impaired in GABAergic interneurons, it leads to reduced threshold and accelerated propagation in febrile seizures, and reduced threshold in flurothyl-induced seizures [19]. As a consequence, enhancement of GABAergic function has an anticonvulsant effect, as exhibited by the mechanism of action and efficacy of many antiepileptic drugs (AEDs).

\section{Optogenetic excitation of GABAergic interneurons for seizure suppression}

In accordance with the concept that the excitatory/inhibitory balance shifts towards the excitatory regime in epilepsy, recent optogenetic studies aim to enhance the inhibitory function of GABAergic interneurons to suppress seizures. Amongst these works, Ledri et al. [3] selectively activated interneuron populations in hippocampal slices, suppressing epileptiform activity induced by 4-aminopyridine (4-AP) or by zero $\mathrm{Mg}^{2+}$. Interestingly, selective activation of only a subpopulation of GABAergic interneurons was not as effective in suppressing seizures. In contrast, closed-loop optogenetic activation of a subtype of GABAergic neurons, the parvalbumin (PV)-containing cells (representing 5\% of hippocampal neurons) eliminated seizures in the hippocampus [1]. Ladas et al. [20] found that activating GADexpressing interneurons with low frequency laser stimulation can attenuate epileptiform activity in the hippocampus.

A few studies combined optogenetics and stem cell transplantation technology to apply inhibitory input to the hyper-excitatory circuits. Activation of GABAergic interneuron grafts led to a suppression of pharmacoresistant seizures in the dentate gyrus (DG), due to the enhancement of synaptic inhibition in this area [21]. Cunningham et al. [22] demonstrated that human pluripotent stem cell (hPSC)-derived maturing GABAergic interneurons (mGINs) could migrate and integrate into the dysfunctional circuity of mouse brain. Using optogenetics, they found that the grafted mGINs could cause postsynaptic inhibitory responses in the host hippocampal neurons. Interestingly, these grafted neurons were already effective in suppressing seizures and ameliorating abnormalities, including cognitive deficits, aggressiveness, and hyperactivity, prior to full electrophysiological maturation.

New view: context-dependent roles of GABAergic cells in controlling postsynaptic excitability and seizure

The traditional view that GABAergic neurons are always "inhibitory" in epilepsy is consistently challenged. The most striking evidence comes from reports suggesting that instead of being quiescent during seizure, GABAergic interneurons may be active. Interneurons (such as 
the somatostatin-positive subtype) can be activated in response to a 4-AP-induced seizure [23, 24]. The excitability of somatostatin-positive interneurons is higher than that of regular spiking pyramidal neurons in response to various activating stimuli, including extracellular current, low- $\mathrm{Mg}^{2+} / \mathrm{Ca}^{2+}$ artificial cerebrospinal fluid, metabotropic glutamate receptor agonists, and cholinergic agonists [25]. In addition, spontaneous GABAergic inhibition is increased in the soma of pyramidal neurons in temporal lobe epilepsy (TLE), although it is reduced in the dendritic regions of the pyramidal cells [26]. Thind et al. [27] further described an initial loss and later an excess growth of GABAergic synapses in dentate granule cells in a rat model of temporal lobe epilepsy. In addition, Marchionni and Maccaferri [28] showed that $\mathrm{GABA}_{\mathrm{A}}$ receptor-mediated perisomatic input is enhanced during seizure. These results suggest that epilepsy might be associated with not fewer but rather abundant dysfunctional GABAergic synapses. Some authors hypothesized that these GABAergic inputs are essential in the generation of pathological, epileptic network activity [28].

At the single cell level, emerging evidence also demonstrates that functional output of GABAergic interneurons could be context dependent. GABAergic neurons can excite as well as inhibit postsynaptic neurons, depending on the states of presynaptic and postsynaptic cells. There are at least four different ways through which GABAergic interneurons could apply "excitatory" effects on network activity. (1) Raising of reversal potential. GABAergic interneurons apply excitatory input to postsynaptic principal neurons, due to an increase in the reversal potential in the principal neurons. (2) Exhaustion of presynaptic GABA. High frequency firing of the GABAergic interneuronsexhausts the presynaptic neurotransmitter GABA, which prevents the postsynaptic principal neurons from being inhibited, instead allowing for their hyper-excitability. (3)
Desynchronization of the principal cells. GABAergic interneurons are responsible for the synchronized firing of principal neurons. (4) Some GABAergic interneurons inhibit other interneurons, causing disinhibition of pyramidal neurons and network hyperexcitability.

\section{Raising of reversal potential (Fig. 1)}

GABAergic interneurons can excite and inhibit postsynaptic neurons, depending on the GABA reversal potential in the postsynaptic cells $[29,30]$. It is well known that GABA transmission depolarizes neonatal neurons owing to the high concentration of intracellular $\mathrm{Cl}^{-}$at this stage $[8,23$, 31-35]. The depolarizing action of GABA is not limited to neonates but can happen whenever $\mathrm{Cl}^{-}$levels increase inside a segment of a mature cell [36]. For example, terminals from GABAergic axo-axonic cells contact with cortical principal neurons at their axon initial segments (AIS). They produce excitatory input to the AIS. However, there is an increased $\mathrm{Cl}^{-}$gradient along the axo-somatodendritic direction, and the reversal potential for GABA $\left(E_{\mathrm{GABA}}\right)$ values decrease from the AIS to the soma and dendrites [37]. This heterogeneity of the GABA reversal potential in postsynaptic cell segments renders the spatially-distinct presynaptic inputs to generate postsynaptic responses with different magnitudes and polarities.

Intracellular $\mathrm{Cl}^{-}$concentration can be mediated by many cellular/molecular mechanisms. During early mammalian embryonic development, the level of $\mathrm{Na}^{+} / \mathrm{K}^{+}$chloride cotransporter 1 (NKCC1) is high, and the level of potassium chloride cotransporter 2 (KCC2) expression is low [38]. This causes a high concentration of intracellular $\mathrm{Cl}^{-}$and depolarization of $E_{\mathrm{GABA}}$. An increase in $\mathrm{KCC} 2$ expression is associated with a reduction in intracellular $\mathrm{Cl}^{-}$and hyperpolarization of $E_{\mathrm{GABA}}$. Both NKCC1 and KCC2 play significant pathological roles in regulating $\mathrm{Cl}^{-}$homeostasis in epileptogenesis within neonatal

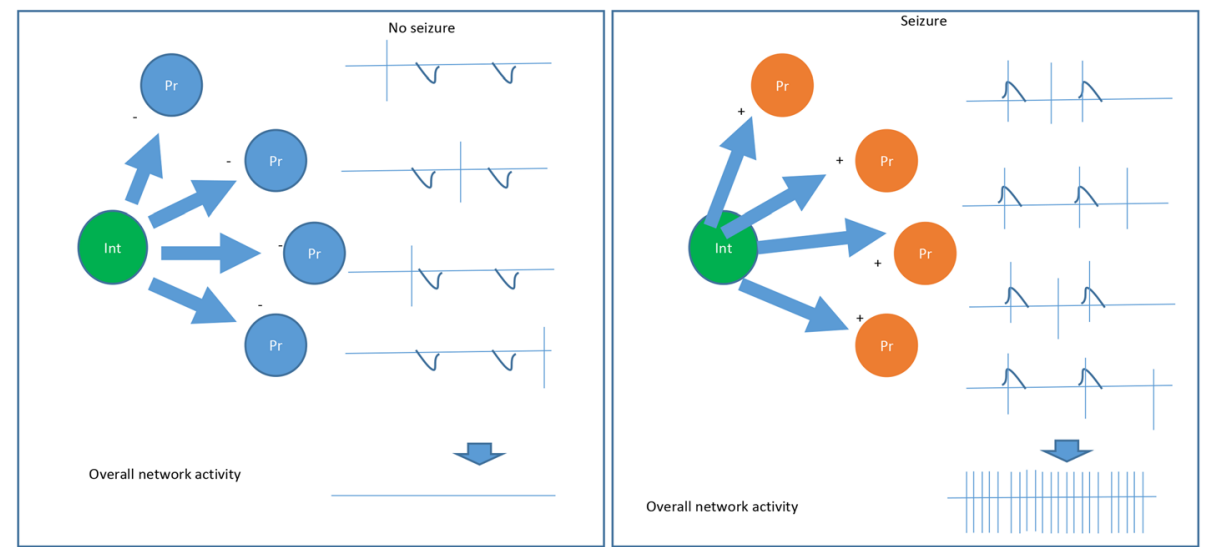

Fig. 1 Epileptogenesis via raised reversal potential to GABAergic current. GABAergic interneurons (Int) apply excitatory synaptic input to the principal neurons $(\operatorname{Pr})$ via raised GABA reversal potential in the principal neurons, which in turn increase the whole network activity and induce seizure. (+) excitatory; (-) inhibitory. Downward deflection trace: inhibitory postsynaptic potential (IPSP). Vertical line: action potential 
brain, and are proposed as potential targets for neonatal seizures $[39,40]$.

NKCC1 and KCC2 also play significant pathological roles in adult epileptogenesis. In drug-resistant temporal lobe epilepsy patients, up-regulation of NKCC1 mRNA was observed in the hippocampal subiculum, which contributed to the depolarized $E_{\mathrm{GABA}}$ [41]. Similarly, over-activation of NKCC1 in neurons of animal models was responsible for depolarizing $E_{\mathrm{GABA}}$, an impairing cortical inhibitory network, and triggering seizure in the presence of ammonia [42]. Following status epilepticus, upregulation of NKCC1 was observed in the deep entorhinal cortex, which contributed to the depolarizing shift of the inhibitory postsynaptic potential reversal in layer 5 neurons [43]. Genetic deletion or inhibition of NKCC1 were found to be neuroprotective against epileptogenesis [42]. NKCC1 inhibition with bumetanide prevented seizure-induced neuronal $\mathrm{Cl}^{-}$accumulation and the consequent facilitation of recurrent seizures in neonatal rats [44]. Bumetanide also prevented granule cell ectopia in the dentate gyrus after febrile seizures, and the development of epilepsy [45].

In contrast to the upregulation of $\mathrm{NKCC} 2$ in the epileptic brain, reduction of KCC2 is another important reason for $\mathrm{Cl}^{-}$accumulation in experimental [46] and human epilepsy [41, 47, 48]. In humans, KCC2 is down regulated in intractable epilepsy caused by focal cortical dysplasia [49]. Subicular pyramidal cells in patients from mesial temporal lobe epilepsy exhibit depolarizing $\mathrm{GABA}_{\mathrm{A}} \mathrm{R}$-mediated postsynaptic events, which are associated with decreased $\mathrm{KCC} 2$ expression [48]. In animals models, decreased KCC2 expression and impaired $\mathrm{Cl}^{-}$ extrusion were also found in pyramidal neurons of injured epileptogenic rat neocortex [50]. Diminished expression of KCC2 in dentate granule (DG) cells persisted for weeks in pilocarpine-induced epilepsy. This caused reduction in the inhibitory efficacy and enhancement in DG cell excitability [51]. In a mouse glioma model, the amount of parvalbumin-positive GABAergic interneurons was significantly reduced [52]. The remaining peritumoral neurons displayed elevated intracellular $\mathrm{Cl}^{-}$levels and consequently, excitatory GABA responses. In these remaining neurons, KCC2 was significantly decreased. The reduced KCC2 immunoreactivity and mRNA expression [46] were associated with more positive $E_{\mathrm{GABA}}$ in epileptic tissue. The molecular mechanism for the loss of KCC2 function is related to $\mathrm{N}$-Methyl-D-aspartic acid (NMDA) receptor activity and $\mathrm{Ca}^{2+}$ influx that dephosphorylate the $\mathrm{KCC} 2$ residue Ser940 [53].

Unbalanced $\mathrm{NKCC} 1 / \mathrm{KCC} 2$ is not the only mechanism for intracellular $\mathrm{Cl}^{-}$accumulation. When firing at high frequency, interneurons can activate the postsynaptic neurons excessively and cause chloride accumulation to depolarizing concentrations in the postsynaptic neurons, making $\mathrm{GABA}_{\mathrm{A}}$ synapses excitatory $[29,54-56]$. As such, GABA can provide the main post-tetanic excitatory drive to pyramidal neurons in the CA1 area of an adult hippocampus [54]. Lillis et al. [14] reported that intracellular $\mathrm{Cl}^{-}$concentration largely increases in pyramidal neurons in mouse hippocampal slices during ictogenesis. Excitatory GABAergic interneurons can form a "positive feedback circuit" with the glutamatergic pyramidal cells within the strata oriens and/or pyramidale of the hippocampal CA1 region, resulting in neuronal synchronization and epileptic afterdischarge [55]. In CA3 pyramidal cells, a large depolarization in the $\mathrm{GABA}_{\mathrm{A}}$ reversal potential occurs when the network enters an interictal state in a low $\mathrm{Mg}^{+} / \mathrm{high} \mathrm{K}^{+}$recurrent seizure model [57]. Clinically, the excitatory effects of GABAergic interneurons have contributed to tumor associated epilepsy [52].

\section{Exhaustion of presynaptic GABA (Fig. 2)}

Continuous activity in GABAergic interneurons could lead to transient GABA depletion, preventing their ability to inhibit pyramidal cells. By recording inhibitory postsynaptic currents (IPSCs) from rat CA3 pyramidal neurons in $10 \mathrm{mM} \mathrm{KCl}$, Shin et al. [58] found that hyper-excitability in pyramidal neurons is related to the diminish of IPSCs mediated by $\mathrm{GABA}_{\mathrm{A}}$ receptors. Recently, we found that high frequency firing in GABAergic interneurons could cause the exhaustion of the presynaptic neurotransmitter GABA in a low $\mathrm{Mg}^{2+} /$ high $\mathrm{K}^{+}$seizure model, therefore leading to the transition of network activity to seizure [57]. Computer simulation predicted that certain focal seizures could be triggered by GABA depletion [59]. It remains to be seen if depletion of presynaptic GABA is presented in in vivo animal models of seizure.

Depletion of presynaptic GABA could be monitored by the frequency of asynchronous release. Jiang et al. [60] reported that asynchronous GABA release occurs at all GABAergic synapses in fast-spiking interneurons. Asynchronous GABA release results in tonic inhibition at interneuron-principal neuron synapses in the hippocampus $[61,62]$. In a genetic mouse model of epilepsy, asynchronous GABA release is found to protect the postsynaptic cell by extending the length of inhibition. Depletion of presynaptic GABA could suppress spontaneous IPSCs [63]. A substantial decrease in asynchronous GABA release results in the loss of tonic inhibition in the hippocampus of Synapsin $\mathrm{II}^{-/-}$mice, prompting hyperexcitability and epileptogenesis [64]. In summary, GABA depletion decreases the inhibitory strength that interneurons apply on the principal cells.

\section{Synchronization of principal cells (Fig. 3)}

GABAergic interneurons can synchronize network activity during seizure [16]. First, GABAergic interneurons 

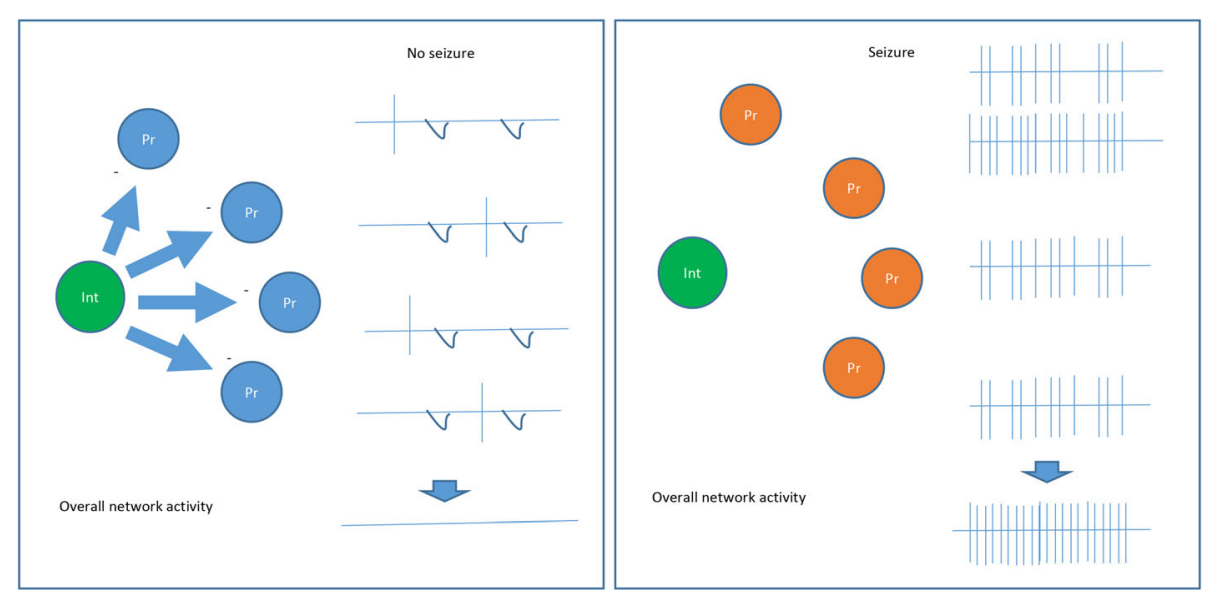

Fig. 2 Epileptogenesis via depletion of presynaptic neurotransmitter GABA. Postsynaptic principal cell firing is enhanced due to the depletion of the presynaptic GABA and release of inhibition. (-) inhibitory

themselves are synchronized by gap-junctions or longrange-projections. It is likely that one individual interneuron can electrically couple to 20-50 others [65], a significant number implying that each interneuron participates in a large, continuous syncytium. Indeed, somatostatin-positive interneurons are electrically coupled via gap-junctions $[25,65,66]$, which synchronize activities between coupled neurons [66] in the neocortex. Alternatively, interneurons could be synchronized by long-rangeprojecting GABAergic neurons from cortical areas. GABAergic neurons provide long-range, bidirectional hippocampal-entorhinal connectivity [67]. A group of long-range GABA neurons, the hippocamposeptal neurons, excite the hippocampal interneurons at the onset of epileptiform activity in immature septohippocampal formation [68].

Secondly, interneurons play a notable role in synchronizing principal cell activity and overall neural network behavior. It is found that principal cells fire synchronously with the interneurons during epileptiform discharges [69, 70]. Since each GABAergic interneuron can have contact with over 1000 pyramidal neurons in the hippocampus, these pyramidal cells may share a common temporal reference established by the same interneuron [71]. Indeed, firing of principal cells is synchronized by interneurons during high-frequency oscillation in the hippocampal network [71-74]. Furthermore, it has been shown that inhibitory interneurons synchronize the large principal neuronal population in seizure $[8,70,75-77]$.

\section{Disinhibition by other interneurons (Fig. 4)}

GABAergic interneurons are capable of targeting other inhibitory neurons, and release these neurons' inhibitory effects to principal cells [78, 79]. For example, when optogenetic techniques are used to activate vasoactive intestinal peptide (VIP) interneurons, it is found that VIP interneurons inhibit somatostatin and some parvalbumin interneurons, which in turn releases these neurons' inhibition to pyramidal and principal cells [80, 81]. Owen et al. [82] demonstrated that depolarizing fast-
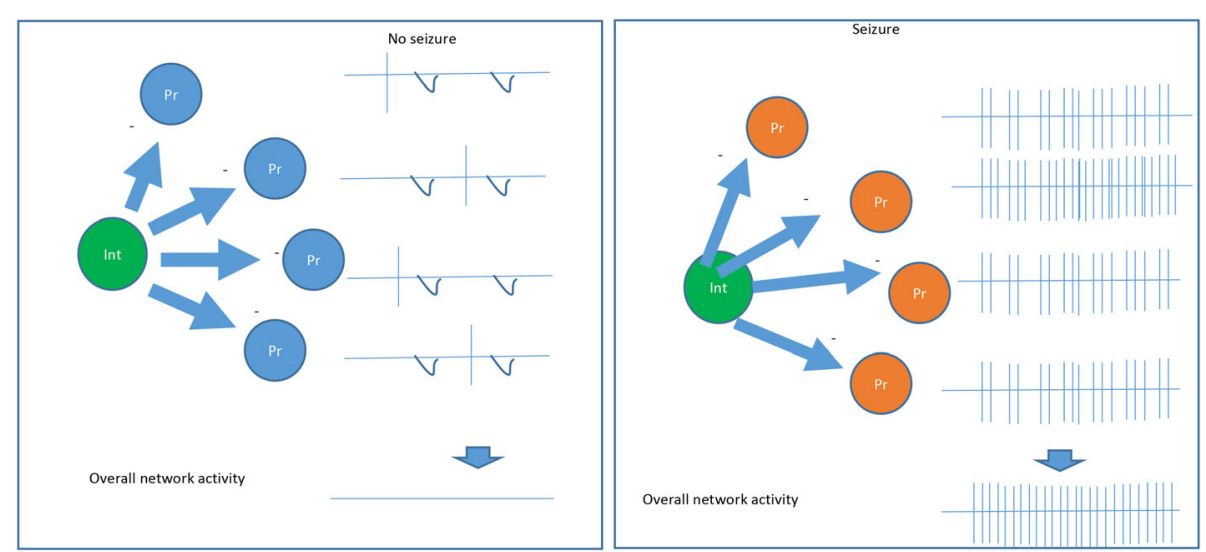

Fig. 3 Epileptogenesis via synchronization of the principal cell (Pr) activity through GABAergic interneurons (Int). (-) inhibitory 


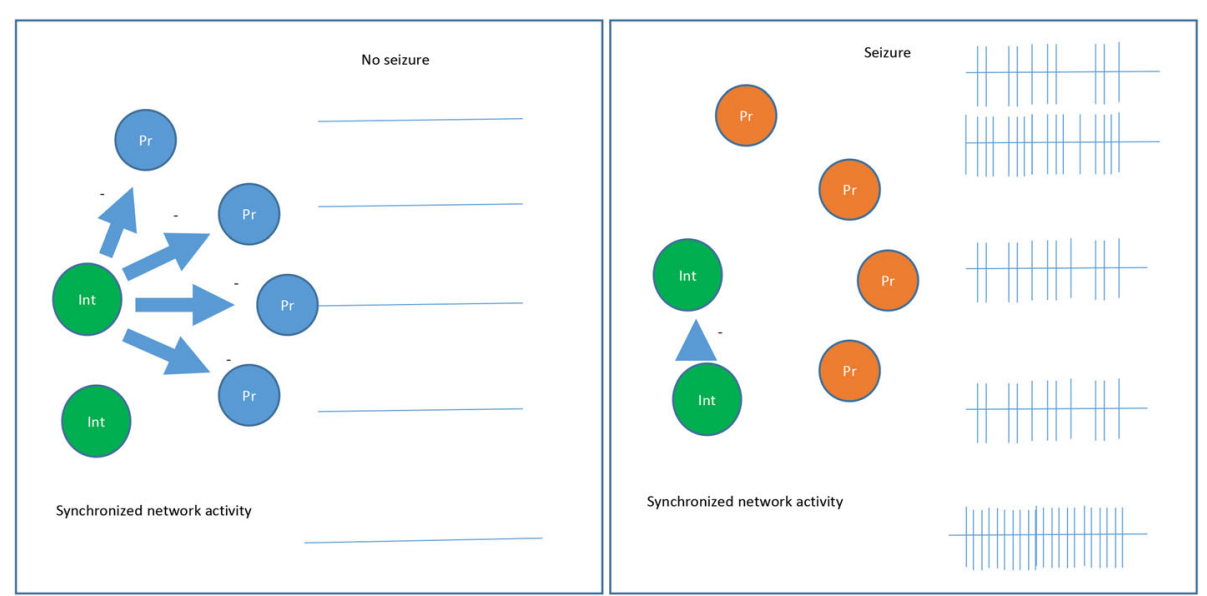

Fig. 4 Epileptogenesis via imbibition of GABAergic interneurons. Some interneurons are inhibited by others, causing dis-inhibition of the principle cells and hyper-excitability. (-) inhibitory

spiking interneurons elevates the rate of GABA release, which leads to the short-term depression of inhibitory connections onto the excitatory cells in the hippocampus. In layer IV of the neocortex, fast spiking parvalbumin interneurons control pyramidal cell activity. Stimulation of somatostatin-expressing GABAergic interneurons inhibits these fast spiking interneurons, which, in turn, disinhibits pyramidal cells [79].

The "disinhibition" hypothesis for epileptogenesis implies that removal of inhibition to the pyramidal cell could cause excitability and seizure susceptibility $[83,84]$. For example, deficits in $\delta$-subunit expression in the $\mathrm{GABA}_{\mathrm{A}}$ receptor of GAD65-positive interneurons result in a reduction of the tonic inhibition to these neurons. Disinhibition of interneurons results in decreased seizure susceptibility [84]. It is unknown if one can initiate seizure by enhancing GABAergic inhibition to certain interneurons, and in turn, removing these interneurons' inhibitory effects on the principal cells. Furthermore, it is unknown if optogenetics can be used to subdue seizure, by suppressing GABAergic interneuron activity, which permits the inhibitory effects of other interneurons be fully applied to principle cells.

\section{Optogenetic inhibition of GABAergic interneurons for seizure suppression}

The context-dependent, excitatory roles that GABAergic interneurons can play, suggest a novel optogenetic strategy for seizure suppression. The widely used protocol that aims at "exciting" GABAergic neurons, is probably not optimal. Instead, this evidence begs for the investigation of seizure suppression by inhibiting these neurons. Using vGAT:ChR2-eYFP mice (expressing ChR2 under the interneuron-specific mouse vesicular GABA transporter (vGAT) promotor) and a local 4-AP microinjection seizure model (performed in the somatosensory cortex), Dufour and Valiante [85] found that optical activation of GABAergic interneurons could lead to seizure. The researchers speculated that the effects of the GABAergic interneurons are context dependent, contingent on the brain activity state. This observation started to challenge the traditionally accepted inhibitory effects of GABAergic interneurons in seizure. Unfortunately, the authors have not tested if optogenetic inhibition of GABAergic interneurons can suppress seizure.

We utilized a Gad2-Cre recombinase mouse line and injected an adeno-associated viral vector (AAV5-EF1 $\alpha$-DIONpHR3.0-eYFP, University of North Carolina vector core facility) into the CA3 area in the hippocampus (2 months old), resulting in expression of the light-sensitive chloride pump halorhodopsin (NpHR) in GABAergic interneurons. The functional role of GABAergic interneurons is investigated in a 4-AP seizure model $(6 \mathrm{mg} / \mathrm{Kg}$ i.p. injection, five animals) by optically inhibiting these neurons. Seizure-like activity was observed 10-15 $\mathrm{min}$ after 4-AP injection. In early approaches, we applied continuous laser inhibition (1 min in duration, adapted from [86]) to the GABAergic interneurons. We observed subtle but quantifiable suppression of electroencephalogram (EEG), which can only be identified through a complicated EEG detection algorithm [87]. To improve the success rate of seizure suppression, we used a high-frequency stimulation (HFS) protocol [88] to inhibit GABAergic interneurons in the CA3 area during 4AP seizure. We found that $10 \mathrm{~ms}$ laser pulses are effective in seizure suppression. In total, we applied 43 HFS (laser train duration $20 \mathrm{~s}$, frequency $20 \mathrm{~Hz}$, pulse width $10 \mathrm{~ms}$, intensity $15 \mathrm{~mW} / \mathrm{mm}^{2}$ ) in 5 different Gad 2 mice. We found that $31(72.1 \%)$ of these HFS trains were effective or partially effective in suppressing seizure EEG. 11 (25.6\%) of the trials were not effective, and 1 (2.3\%) corresponded with enhanced seizure activity. Figure 5 shows several examples when seizure EEG was suppressed when GABAergic 

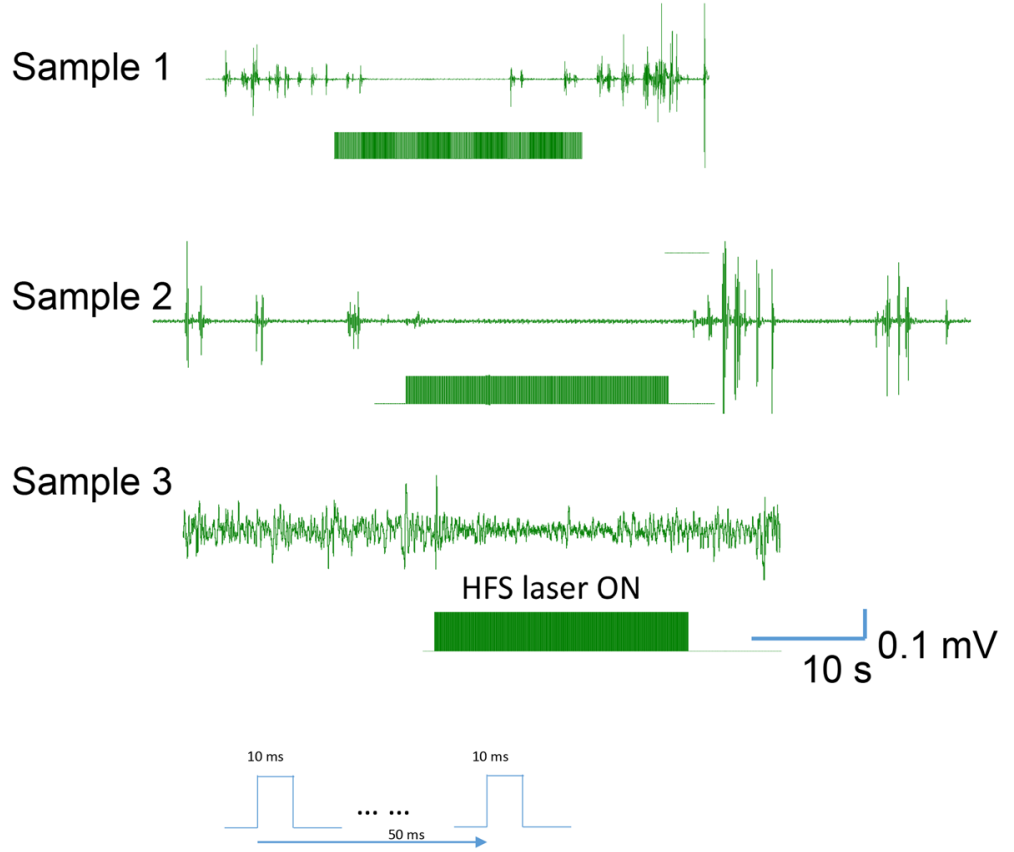

Fig. 5 High frequency laser trains are effective in suppressing 4-AP seizure in hippocampal CA3 area in vivo. Bar: High frequency laser stimulation ( $20 \mathrm{~Hz}, 10 \mathrm{~ms}$ pulse width and 20s duration). Examples 1 and 2: complete seizure EEG suppression. Example 3: Partial suppression of seizure activity. Overall, $72.1 \%$ of the HFS trial are effective in seizure EEG suppression

interneurons were inhibited with HFS. We are currently exploring the optimal parameters to further improve the success rate for seizure suppression, and investigate the cellular mechanism of such suppression.

\section{Conclusion}

GABAergic neurotransmission has been traditionally regarded as inhibitory to neural network activity, and the idea that failure of GABA inhibition contributes to seizure has been dominant, and sometimes presumable. The context-dependent, possibly "excitatory" roles that the GABAergic interneurons can play in epileptic tissue, begs for the reassessment of their contribution using optogenetic tools, which can provide precise spatial and temporal control of neuronal activity with excellent resolutions. New optogenetic protocols aimed at "inhibiting" GABAergic interneurons should be explored to investigate the possibility of seizure suppression.

\section{Abbreviations}

4-AP: 4-aminopyridine; AEDs: Antiepileptic drugs; AIS: Axon initial segments; DG: Dentate granule; $E_{G A B A}$ : Reversal potential for GABA; GABA: GammaAminobutyric acid; HFS: High-frequency stimulation; hPSC: Human pluripotent stem cell; IPSCs: Inhibitory postsynaptic currents; KCC2: Potassium chloride cotransporter 2; mGINs: Maturing GABAergic interneurons; NKCC1: $\mathrm{Na}^{+} / \mathrm{K}^{+}$chloride cotransporter 1; NMDA: N-Methyl-D-aspartic acid; NpHR: Halorhodopsin; PV: Parvalbumin; TLE: Temporal lobe epilepsy; VGAT: Vesicular GABA transporter; VIP: Vasoactive intestinal peptide

\section{Acknowledgements}

The authors thank Dr. Peter Carlen for valuable comments in the earlier stage of the manuscripts. We thank Dr. Stephan Steidl and Ben Foote-Huth for their assistance in obtaining preliminary optogenetic results.

\section{Funding}

The work is supported by the startup fund of Loyola University Chicago.

\section{Availability of data and materials}

All data generated or analyzed during this study are included in this published article.

\section{Authors' contributions}

HY and SK drafted the manuscript. Both authors read and approved the final manuscript.

\section{Ethics approval and consent to participate}

Not applicable.

\section{Consent for publication}

Not applicable.

\section{Competing interests}

The authors declare that they have no competing interests.

\section{Publisher's Note}

Springer Nature remains neutral with regard to jurisdictional claims in published maps and institutional affiliations.

Received: 20 September 2017 Accepted: 28 November 2017

Published online: 05 December 2017

\section{References}

1. Krook-Magnuson E, Armstrong C, Oijala M, Soltesz I. On-demand optogenetic control of spontaneous seizures in temporal lobe epilepsy. Nat Commun. 2013;4:1376 
2. Berglind F, Ledri M, Sorensen AT, Nikitidou L, Melis M, Bielefeld P, Kirik D, Deisseroth K, Andersson M, Kokaia M. Optogenetic inhibition of chemically induced hypersynchronized bursting in mice. Neurobiol Dis. 2014;65:133-41.

3. Ledri M, Madsen MG, Nikitidou L, Kirik D, Kokaia M. Global optogenetic activation of inhibitory interneurons during epileptiform activity. J Neurosci. 2014:34:3364-77.

4. Ziburkus J, Cressman JR, Barreto E, Schiff SJ. Interneuron and pyramidal cell interplay during in vitro seizure-like events. J Neurophysiol. 2006;95:3948-54.

5. Reid CA, Berkovic SF, Petrou S. Mechanisms of human inherited epilepsies. Prog Neurobiol. 2009;87:41-57.

6. Epsztein J, Milh M, Bihi Rl, Jorquera I, Ben-Ari Y, Represa A, Crepel V. Ongoing epileptiform activity in the post-ischemic hippocampus is associated with a permanent shift of the excitatory-inhibitory synaptic balance in CA3 pyramidal neurons. J Neurosci. 2006;26:7082-92.

7. Derchansky M, Jahromi SS, Mamani M, Shin DS, Sik A, Carlen PL. Transition to seizures in the isolated immature mouse hippocampus: a switch from dominant phasic inhibition to dominant phasic excitation. J Physiol. 2008;586:477-94.

8. Lasztoczi B, Nyitrai G, Heja L, Kardos J. Synchronization of GABAergic inputs to CA3 pyramidal cells precedes seizure-like event onset in juvenile rat hippocampal slices. J Neurophysiol. 2009;102:2538-53.

9. Huberfeld G, de la Prida LM, Pallud J, Cohen I, Le Van Quyen M, Adam C, Clemenceau S, Baulac M, Miles R. Glutamatergic pre-ictal discharges emerge at the transition to seizure in human epilepsy. Nat Neurosci. 2011;14:627-34.

10. Sutula TP, Dudek FE. Unmasking recurrent excitation generated by mossy fiber sprouting in the epileptic dentate gyrus: an emergent property of a complex system. Prog Brain Res. 2007;163:541-63.

11. Olsen RW, Avoli M. GABA and epileptogenesis. Epilepsia. 1997;38:399-407.

12. DeLorey TM, Olsen RW. GABA and epileptogenesis: comparing gabrb3 gene-deficient mice with Angelman syndrome in man. Epilepsy Res. 1999;36:123-32.

13. de Lanerolle NC, Kim JH, Robbins RJ, Spencer DD. Hippocampal interneuron loss and plasticity in human temporal lobe epilepsy. Brain Res. 1989;495:387-95.

14. Lillis KP, Kramer MA, Mertz J, Staley KJ, White JA. Pyramidal cells accumulate chloride at seizure onset. Neurobiol Dis. 2012;47:358-66.

15. Dinocourt C, Petanjek Z, Freund TF, Ben-Ari Y, Esclapez M. Loss of interneurons innervating pyramidal cell dendrites and axon initial segments in the CA1 region of the hippocampus following pilocarpine-induced seizures. J Comp Neurol. 2003;459:407-25.

16. Avoli M, de Curtis M. GABAergic synchronization in the limbic system and its role in the generation of epileptiform activity. Prog Neurobiol. 2011;95:104-32.

17. Hedrich UB, Liautard C, Kirschenbaum D, Pofahl M, Lavigne J, Liu Y, Theiss S, Slotta J, Escayg A, Dihne M, et al. Impaired action potential initiation in GABAergic interneurons causes hyperexcitable networks in an epileptic mouse model carrying a human $\mathrm{Na}(\mathrm{V}) 1.1$ mutation. J Neurosci. 2014;34:14874-89.

18. Tai C, Abe Y, Westenbroek RE, Scheuer T, Catterall WA. Impaired excitability of somatostatin- and parvalbumin-expressing cortical interneurons in a mouse model of Dravet syndrome. Proc Natl Acad Sci U S A. 2014;111:E3139-48.

19. Martin MS, Dutt K, Papale LA, Dube CM, Dutton SB, de Haan G, Shankar A, Tufik S, Meisler MH, Baram TZ, et al. Altered function of the SCN1A voltagegated sodium channel leads to gamma-aminobutyric acid-ergic (GABAergic) interneuron abnormalities. J Biol Chem. 2010;285:9823-34.

20. Ladas TP, Chiang CC, Gonzalez-Reyes LE, Nowak T, Durand DM. Seizure reduction through interneuron-mediated entrainment using low frequency optical stimulation. Exp Neurol. 2015;269:120-32.

21. Henderson KW, Gupta J, Tagliatela S, Litvina E, Zheng X, Van Zandt MA, Woods N, Grund E, Lin D, Royston S, et al. Long-term seizure suppression and optogenetic analyses of synaptic connectivity in epileptic mice with hippocampal grafts of GABAergic interneurons. J Neurosci. 2014;34:13492-504.

22. Cunningham M, Cho JH, Leung A, Savvidis G, Ahn S, Moon M, Lee PK, Han JJ, Azimi N, Kim KS, et al. hPSC-derived maturing GABAergic interneurons ameliorate seizures and abnormal behavior in epileptic mice. Cell Stem Cell. 2014;15:559-73.

23. Lopantsev V, Avoli M. Participation of GABAA-mediated inhibition in ictallike discharges in the rat entorhinal cortex. J Neurophysiol. 1998;79:352-60.

24. Barbarosie M, Louvel J, D'Antuono M, Kurcewicz I, Avoli M. Masking synchronous GABA-mediated potentials controls limbic seizures. Epilepsia. 2002:43:1469-79.
25. Fanselow EE, Richardson KA, Connors BW. Selective, state-dependent activation of somatostatin-expressing inhibitory interneurons in mouse neocortex. J Neurophysiol. 2008;100:2640-52.

26. Cossart R, Dinocourt C, Hirsch JC, Merchan-Perez A, De Felipe J, Ben-Ari Y, Esclapez M, Bernard C. Dendritic but not somatic GABAergic inhibition is decreased in experimental epilepsy. Nat Neurosci. 2001;4:52-62.

27. Thind KK, Yamawaki R, Phanwar I, Zhang G, Wen X, Buckmaster PS. Initial loss but later excess of GABAergic synapses with dentate granule cells in a rat model of temporal lobe epilepsy. J Comp Neurol. 2010;518:647-67.

28. Marchionni I, Maccaferri G. Quantitative dynamics and spatial profile of perisomatic GABAergic input during epileptiform synchronization in the CA1 hippocampus. J Physiol. 2009;587:5691-708.

29. Staley KJ, Soldo BL, Proctor WR. Ionic mechanisms of neuronal excitation by inhibitory GABAA receptors. Science. 1995;269:977-81.

30. Bernard C, Cossart R, Hirsch JC, Esclapez M, Ben-Ari Y. What is GABAergic inhibition? How is it modified in epilepsy? Epilepsia. 2000;41(Suppl 6):S90-5.

31. Kohling R, Vreugdenhil M, Bracci E, Jefferys JG. Ictal epileptiform activity is facilitated by hippocampal GABAA receptor-mediated oscillations. J Neurosci. 2000;20:6820-9.

32. Dzhala VI, Staley KJ. Transition from interictal to ictal activity in limbic networks in vitro. J Neurosci. 2003;23:7873-80

33. Perez Velazquez JL. Bicarbonate-dependent depolarizing potentials in pyramidal cells and interneurons during epileptiform activity. Eur J Neurosci. 2003;18:1337-42.

34. Khalilov I, Le Van Quyen M, Gozlan H, Ben-Ari Y. Epileptogenic actions of GABA and fast oscillations in the developing hippocampus. Neuron. 2005:48:787-96.

35. Fujiwara-Tsukamoto $Y$, Isomura $Y$, Imanishi M, Fukai T, Takada M. Distinct types of ionic modulation of GABA actions in pyramidal cells and interneurons during electrical induction of hippocampal seizure-like network activity. Eur J Neurosci. 2007;25:2713-25.

36. Cherubini E, Gaiarsa JL, Ben-Ari Y. GABA: an excitatory transmitter in early postnatal life. Trends Neurosci. 1991;14:515-9.

37. Khirug S, Yamada J, Afzalov R, Voipio J, Khiroug L, Kaila K. GABAergic depolarization of the axon initial segment in cortical principal neurons is caused by the Na-K-2Cl cotransporter NKCC1. J Neurosci. 2008;28:4635-9.

38. Stil A, Liabeuf S, Jean-Xavier C, Brocard C, Viemari JC, Vinay L. Developmental up-regulation of the potassium-chloride cotransporter type 2 in the rat lumbar spinal cord. Neuroscience. 2009;164:809-21.

39. Kahle KT, Staley KJ. The bumetanide-sensitive Na-K-2Cl cotransporter NKCC1 as a potential target of a novel mechanism-based treatment strategy for neonatal seizures. Neurosurg Focus. 2008;25:E22.

40. Loscher W, Puskarjov M, Kaila K. Cation-chloride cotransporters NKCC1 and KCC2 as potential targets for novel antiepileptic and antiepileptogenic treatments. Neuropharmacology. 2013;69:62-74.

41. Palma E, Amici M, Sobrero F, Spinelli G, Di Angelantonio S, Ragozzino D, Mascia A, Scoppetta C, Esposito V, Miledi R, Eusebi F. Anomalous levels of $\mathrm{Cl}$ - transporters in the hippocampal subiculum from temporal lobe epilepsy patients make GABA excitatory. Proc Natl Acad Sci U S A. 2006;103:8465-8.

42. Rangroo Thrane V, Thrane AS, Wang F, Cotrina ML, Smith NA, Chen M, Xu Q, Kang N, Fujita T, Nagelhus EA, Nedergaard M. Ammonia triggers neuronal disinhibition and seizures by impairing astrocyte potassium buffering. Nat Med. 2013;19:1643-8.

43. Bragin DE, Sanderson JL, Peterson S, Connor JA, Muller WS. Development of epileptiform excitability in the deep entorhinal cortex after status epilepticus. Eur J Neurosci. 2009;30:611-24.

44. Dzhala VI, Kuchibhotla KV, Glykys JC, Kahle KT, Swiercz WB, Feng G, Kuner T, Augustine GJ, Bacskai BJ, Staley KJ. Progressive NKCC1-dependent neuronal chloride accumulation during neonatal seizures. J Neurosci. 2010;30:11745-61.

45. Koyama R, Tao K, Sasaki T, Ichikawa J, Miyamoto D, Muramatsu R, Matsuki N, Ikegaya Y. GABAergic excitation after febrile seizures induces ectopic granule cells and adult epilepsy. Nat Med. 2012;18:1271-8.

46. de Guzman P, Inaba Y, Biagini G, Baldelli E, Mollinari C, Merlo D, Avoli M. Subiculum network excitability is increased in a rodent model of temporal lobe epilepsy. Hippocampus. 2006;16:843-60.

47. Aronica E, Boer K, Redeker S, Spliet WG, van Rijen PC, Troost D, Gorter JA. Differential expression patterns of chloride transporters, $\mathrm{Na}+-\mathrm{K}+-2 \mathrm{Cl}-$ cotransporter and $\mathrm{K}+-\mathrm{Cl}-$ cotransporter, in epilepsy-associated malformations of cortical development. Neuroscience. 2007;145:185-96.

48. Huberfeld G, Wittner L, Clemenceau S, Baulac M, Kaila K, Miles R, Rivera C. Perturbed chloride homeostasis and GABAergic signaling in human temporal lobe epilepsy. J Neurosci. 2007;27:9866-73. 
49. Shimizu-Okabe C, Tanaka M, Matsuda K, Mihara T, Okabe A, Sato K, Inoue Y, Fujiwara T, Yagi K, Fukuda A. KCC2 was downregulated in small neurons localized in epileptogenic human focal cortical dysplasia. Epilepsy Res. 2011:93:177-84

50. Jin X, Huguenard JR, Prince DA. Impaired Cl- extrusion in layer V pyramidal neurons of chronically injured epileptogenic neocortex. J Neurophysiol. 2005;93:2117-26.

51. Pathak HR, Weissinger F, Terunuma M, Carlson GC, Hsu FC, Moss SJ, Coulter DA. Disrupted dentate granule cell chloride regulation enhances synaptic excitability during development of temporal lobe epilepsy. J Neurosci. 2007;27:14012-22.

52. Campbell SL, Robel S, Cuddapah VA, Robert S, Buckingham SC, Kahle KT, Sontheimer H. GABAergic disinhibition and impaired KCC2 cotransporter activity underlie tumor-associated epilepsy. Glia. 2015;63:23-36.

53. Lee HH, Deeb TZ, Walker JA, Davies PA, Moss SJ. NMDA receptor activity downregulates KCC2 resulting in depolarizing GABAA receptor-mediated currents. Nat Neurosci. 2011:14:736-43.

54. Taira T, Lamsa K, Kaila K. Posttetanic excitation mediated by GABA(A) receptors in rat CA1 pyramidal neurons. J Neurophysiol. 1997;77:2213-8.

55. Fujiwara-Tsukamoto Y, Isomura Y, Kaneda K, Takada M. Synaptic interactions between pyramidal cells and interneurone subtypes during seizure-like activity in the rat hippocampus. J Physiol. 2004;557:961-79.

56. Andersen $\mathrm{P}$, Dingledine $\mathrm{R}$, Gjerstad L, Langmoen IA, Laursen AM. Two different responses of hippocampal pyramidal cells to application of gamma-amino butyric acid. J Physiol. 1980;305:279-96.

57. Zhang ZJ, Koifman J, Shin DS, Ye H, Florez CM, Zhang L, Valiante TA, Carlen $\mathrm{PL}$. Transition to seizure: ictal discharge is preceded by exhausted presynaptic GABA release in the hippocampal CA3 region. J Neurosci. 2012;32:2499-512.

58. Shin DS, Yu W, Sutton A, Calos M, Carlen PL. Elevated potassium elicits recurrent surges of large GABAA-receptor-mediated post-synaptic currents in hippocampal CA3 pyramidal neurons. J Neurophysiol. 2011;105:1185-98.

59. Ho ECY, Truccolo W. Interaction between synaptic inhibition and glialpotassium dynamics leads to diverse seizure transition modes in biophysical models of human focal seizures. J Comput Neurosci. 2016;41:225-44.

60. Jiang M, Zhu J, Liu Y, Yang M, Tian C, Jiang S, Wang Y, Guo H, Wang K, Shu $Y$. Enhancement of asynchronous release from fast-spiking interneuron in human and rat epileptic neocortex. PLoS Biol. 2012;10:e1001324.

61. Hefft $S$, Jonas P. Asynchronous GABA release generates long-lasting inhibition at a hippocampal interneuron-principal neuron synapse. Nat Neurosci. 2005:8:1319-28

62. Fang $\mathrm{Q}$, Chen Z. Increased asynchronous GABA release causes more inhibition in human epileptic brain? Acta Pharmacol Sin. 2012;33:859-60.

63. Aiba I, Shuttleworth CW. Characterization of inhibitory GABA-A receptor activation during spreading depolarization in brain slice. PLOS One. 2014;9:e110849.

64. Medrihan L, Ferrea E, Greco B, Baldelli P, Benfenati F. Asynchronous GABA release is a key determinant of tonic inhibition and controls neuronal excitability: a study in the Synapsin II-/- mouse. Cereb Cortex. 2015;25:3356-68.

65. Amitai Y, Gibson JR, Beierlein M, Patrick SL, Ho AM, Connors BW, Golomb D. The spatial dimensions of electrically coupled networks of interneurons in the neocortex. J Neurosci. 2002;22:4142-52.

66. Carlen PL, Skinner F, Zhang L, Naus C, Kushnir M, Perez Velazquez JL. The role of gap junctions in seizures. Brain Res Brain Res Rev. 2000;32:235-41.

67. Melzer S, Michael M, Caputi A, Eliava M, Fuchs EC, Whittington MA, Monyer H. Long-range-projecting GABAergic neurons modulate inhibition in hippocampus and entorhinal cortex. Science. 2012;335:1506-10.

68. Quilichini PP, Le Van Quyen M, Ivanov A, Turner DA, Carabalona A, Gozlan $H$, Esclapez M, Bernard C. Hub GABA neurons mediate gamma-frequency oscillations at ictal-like event onset in the immature hippocampus. Neuron. 2012;74:57-64

69. Esclapez M, Hirsch JC, Khazipov R, Ben-Ari Y, Bernard C. Operative GABAergic inhibition in hippocampal CA1 pyramidal neurons in experimental epilepsy. Proc Natl Acad Sci U S A. 1997;94:12151-6.

70. Velazquez JL, Carlen PL. Synchronization of GABAergic interneurona networks during seizure-like activity in the rat horizontal hippocampal slice. Eur J Neurosci. 1999:11:4110-8.

71. Cobb SR, Buhl EH, Halasy K, Paulsen O, Somogyi P. Synchronization of neuronal activity in hippocampus by individual GABAergic interneurons. Nature. 1995;378:75-8
72. Buzsaki G, Horvath Z, Urioste R, Hetke J, Wise K. High-frequency network oscillation in the hippocampus. Science. 1992;256:1025-7.

73. Csicsvari J, Hirase H, Czurko A, Mamiya A, Buzsaki G. Oscillatory coupling of hippocampal pyramidal cells and interneurons in the behaving rat. J Neurosci. 1999;19:274-87.

74. Whittington MA, Traub RD, Jefferys JG. Synchronized oscillations in interneuron networks driven by metabotropic glutamate receptor activation. Nature. 1995;373:612-5.

75. Beenhakker MP, Huguenard JR. Neurons that fire together also conspire together: is normal sleep circuitry hijacked to generate epilepsy? Neuron. 2009;62:612-32

76. Gnatkovsky V, Librizzi L, Trombin F, de Curtis M. Fast activity at seizure onset is mediated by inhibitory circuits in the entorhinal cortex in vitro. Ann Neurol, 2008;64:674-86.

77. Khazipov R, Khalilov I, Tyzio R, Morozova E, Ben-Ari Y, Holmes GL. Developmental changes in GABAergic actions and seizure susceptibility in the rat hippocampus. Eur J Neurosci. 2004;19:590-600.

78. Somogyi P, Kisvarday ZF, Martin KA, Whitteridge D. Synaptic connections of morphologically identified and physiologically characterized large basket cells in the striate cortex of cat. Neuroscience. 1983;10:261-94.

79. Tremblay R, Lee S, Rudy B. GABAergic interneurons in the neocortex: from cellular properties to circuits. Neuron. 2016:91:260-92.

80. Karnani MM, Jackson J, Ayzenshtat I, Hamzehei Sichani A, Manoocheri K, Kim S, Yuste R. Opening holes in the blanket of inhibition: localized lateral disinhibition by VIP Interneurons. J Neurosci. 2016;36:3471-80.

81. Pi HJ, Hangya B, Kvitsiani D, Sanders JI, Huang ZJ, Kepecs A. Cortical interneurons that specialize in disinhibitory control. Nature. 2013;503:521-4.

82. Owen SF, Tuncdemir SN, Bader PL, Tirko NN, Fishell G, Tsien RW. Oxytocin enhances hippocampal spike transmission by modulating fast-spiking interneurons. Nature. 2013;500:458-62.

83. Buckmaster PS, Jongen-Relo AL, Davari SB, Wong EH. Testing the disinhibition hypothesis of epileptogenesis in vivo and during spontaneous seizures. J Neurosci. 2000;20:6232-40.

84. Lee V, Maguire J. Impact of inhibitory constraint of interneurons on neuronal excitability. J Neurophysiol. 2013;110:2520-35.

85. Mantoan Ritter L, Golshani P, Takahashi K, Dufour S, Valiante T, Kokaia M. WONOEP appraisal: optogenetic tools to suppress seizures and explore the mechanisms of epileptogenesis. Epilepsia. 2014;55:1693-702.

86. Sukhotinsky I, Chan AM, Ahmed OJ, Rao VR, Gradinaru V, Ramakrishnan C, Deisseroth K, Majewska AK, Cash SS. Optogenetic delay of status epilepticus onset in an in vivo rodent epilepsy model. PLoS One. 2013;8:e62013.

87. Wu Q, Fote-Huth B, Steidl S, Ye H, Zhao W. EEG analysis reveals reduced seizure activity by optogenetic inhibition of GABAergic interneurons. Banff, Canada: IEEE International Conference on System, Man and Cybernetics; 2017.

88. Chiang CC, Ladas TP, Gonzalez-Reyes LE, Durand DM. Seizure suppression by high frequency optogenetic stimulation using in vitro and in vivo animal models of epilepsy. Brain Stimul. 2014;7:890-9.

\section{Submit your next manuscript to BioMed Central and we will help you at every step:}

- We accept pre-submission inquiries

- Our selector tool helps you to find the most relevant journal

- We provide round the clock customer support

- Convenient online submission

- Thorough peer review

- Inclusion in PubMed and all major indexing services

- Maximum visibility for your research

Submit your manuscript at www.biomedcentral.com/submit
C) Biomed Central 